Cuad. Invest. Filol., 43 (2017), 191-207. http://doi.org/10.18172/cif.2987

\title{
LA NOVELA DE CAMPUS EN ESPAÑA 2000-2015
}

\author{
Susana Gil-Albarellos \\ Universidad de Valladolid \\ susana@fyl.uva.es
}

\begin{abstract}
RESUMEN: La novela de campus es un género literario que en España no ha contado con suficiente atención teórica ni literaria; sin embargo, desde hace pocos años, numerosos escritores han centrado las tramas de sus obras en el ámbito universitario, acrecentándose el interés por este tipo de novelas tanto en lectores como en investigadores. Con este trabajo pretendemos dar a conocer las características de algunas de las obras más representativas del género de novela de campus en la literatura española para constatar su incipiente relevancia en el ámbito de la literatura española reciente, así como confirmar su agrupación como género literario consolidado dentro de la narrativa actual.

PALABRAS CLAVE: novela, campus, universidad, narrativa actual, género literario.
\end{abstract}

\section{NOVEL OF CAMPUS IN SPAIN 2000-2015}

ABSTRACT: The campus novel is a literary genre in Spain has not been sufficient theoretical and literary attention; however, for a few years, numerous writers have focused frames of his works at the university level, to accrue interest in this type of novel both readers and researchers. This paper tries to present the characteristics of some of the most representative works of the genre of novel campus in Spanish literature to confirm their emerging relevance in the context of the recent Spanish literature and confirm his group as a literary genre consolidated within of the current narrative.

KEYWORDS: novel, the University campus, actual narrative, literary genre.

Recibido: 20/05/2016. Aceptado: 13/09/2016

La novela de campus en España es un subgénero narrativo que ni ha contado con suficiente desarrollo ni las manifestaciones concretas del mismo han sido estudiadas en conjunto. A pesar de esta circunstancia, es innegable que la literatura española sí cuenta con un repertorio de novela de campus, que si bien ha sido considerado bajo otros membretes genéricos, se cuentan en número sufi- 
ciente para poder extraer ciertos rasgos funcionales. Con este trabajo pretendo advertir de la existencia de un género narrativo reciente que va tomando forma y desarrollo en nuestra literatura, y señalo dar cuenta porque en este primer esbozo voy a tratar cuantificar y estudiar alguna de las novelas que considero fundacionales del género de campus en España que muestran la variedad del mismo en cuanto a tramas y formas.

Como sucede con cualquier agrupación de obras que confluyan en la consideración teórico literaria de género literario, es la distancia histórica y la valoración conjunta de las obras que la forman, dentro de un tiempo y un espacio geográfico concreto, lo que las enmarca en tal género, y así sucede con la novela de campus, que con varias décadas de retraso con respecto a la literatura en inglés, está todavía en formación en la literatura española. En este sentido, afirma Guillén que "Sólo el tiempo histórico puede demostrarnos que un modelo ha llegado efectivamente a erigirse en género” (1985: 150). Con todo, las obras que actualmente pueden ser agrupadas bajo dicho membrete genérico cumplen con ciertos rasgos de género que admiten concebirlas bajo dicha terminología. Dichos rasgos tienen que ver con la amplitud temática, con la consideración de sus personajes -necesariamente vinculados a la institución universitaria-, y con su definición espacio-temporal (cronotopo de M. Bajtín), ya que las novelas están situadas en época más o menos reciente y en un campus universitario, entendido como institución pero también como espacio físico. Por otro lado, la variedad que presentan las distintas tramas de la novela de campus no supone inconveniente en su definición genérica, puesto que todas derivan de un modo u otro de la forma de vivir y convivir en el ámbito universitario. En la universidad tiene lugar el encuentro de muchas personas de diferente edad, sexo y condición, por lo que esa multiplicidad de seres humanos en un mismo espacio y tiempo posibilita desarrollar muchas y diversas tramas que tienen que ver, en última instancia, con el espacio vital que supone la universidad. Además, es oportuno recordar que las obras que integran un género literario lo hacen por afinidad funcional y no argumental (Guillén 1985: 144).

Una condición imprescindible para la consolidación de un género literario es la aceptación por parte de los lectores de estar ante dicho género, es decir, la agrupación de un conjunto de obras bajo un membrete genérico tiene que ver, en última instancia, con la percepción de los receptores de ciertos rasgos comunes en dichos textos literarios que confirman de la existencia del género, y eso lo da el conjunto y no la obra individual. La insistencia en la importancia del lector en la teoría de los géneros literarios ya fue señalado, entre otros, por Claudio 
Guillen, cuando afirma que "Pragmáticamente, o sea desde el punto de vista del lector (o mejor dicho los lectores: el público), el género implica no sólo trato sino contrato” (1985: 147). La novela de campus es un género literario en el que una parte de sus lectores son personas vinculadas a la universidad, al igual que lo son muchos de los autores, y así es concebido en la literatura española actual por parte de quienes se acercan a él.

A pesar de la dificultad a la hora de definir un género literario, sus rasgos diferenciales y fundamentales, hay trabajos que ya han apuntado algún intento de definición de la novela de campus, como la que ofrece acertadamente María Inés Castagnino:

Como características básicas, no puede decirse mucho más que se trata de novelas protagonizadas por académicos (docentes, investigadores o ambas condiciones a la vez) que se desempeñan generalmente en el área de las humanidades, a menudo en la de literatura, y cuya acción suele transcurrir en las dependencias de una universidad (2011: 125).

De esta definición se extraen dos condiciones no excluyentes y sí contantes en el género y que tienen que ver con sus personajes principales, vinculados a la universidad pero no sólo como académicos, como señala Castagnino, sino también como estudiantes, y el marco espacial, un campus universitario.

El nacimiento y desarrollo de la novela de campus tiene lugar en el mundo anglosajón, Reino Unido y Estados Unidos, países en los que ha contado con excelentes muestras y en consecuencia, ha desarrollado un consolidado aparato teórico y el reconocimiento por parte de lectores y críticos. En cuanto a su origen concreto, si bien es cierto que la crítica señala antecedentes en el siglo XIX, principalmente en las novelas de Nathaniel Hawthorne, Fanshawe (1828) en Estados Unidos, y de Anthony Trollope, Barchester Towers (1857) en Inglaterra, lo cierto es que la consolidación del género no se produce hasta pasada la Segunda Guerra Mundial con el impulso de las universidades, que en ese momento amplían su capacidad en el número de estudiantes y, en consecuencia, son más heterogéneas. La mayor parte de los lectores y estudiosos coinciden en señalar cuatro títulos que marcan el comienzo de la novela de campus tal y como la entendemos en la actualidad, asociada a la variedad de la narrativa de ficción contemporánea; dichas obras son The Masters (1951), de C.P. Snow y Lucky Jim (1954), de Kingsley Amis, ambas en Inglaterra, y The Groves of Academe (1951), de Mary McCarthy, y Pictures from an Institution (1954), de Randall Jarrell en Estados Unidos. A éstas han seguido con notable éxito, entre otras, algunas obras de David Lodge, 
sobre todo El mundo es un pañuelo, o de Malcom Bradbury, The History man, por no reiterar el éxito del que en la actualidad goza Stoner de John Williams, que publicada en 1965, conoce ahora una segunda oportunidad.

Es curioso constatar que ya en estas cuatro obras muy representativas del conjunto, las técnicas narrativas son muy variadas, tanto los recursos de quién ve y quién habla como la visión de conjunto de los colleges tanto británicos como estadounidenses, algunos de prestigio y solera, como Cambridge en el caso de Snow, o de provincias, como en la novela de Amis. Con ello se constata que las variedades técnicas y argumentales de las que se sirve la narrativa de campus son muchas y abiertas, por lo que es difícil una coincidencia de rasgos funcionales que permita cierta rigurosidad a la hora de caracterizar el género. Además, cabe señalar las diferencias entre la novela de campus británica y la estadounidense, centrada casi exclusivamente en dos campus la primera: Oxford y Cambridge, y mucho más vinculada a los colleges privados donde la convivencia es muy cercana entre los miembros de la comunidad universitaria en el caso de la novela norteamericana. Las novelas fundacionales del género son de carácter diferente pues los escritores británicos Snow y Amis presentan notables diferencias de fondo y de forma con los autores americanos McCarthy y Jarrell (Showalter, 2005: 13 y ss). C.P. Snow retrata en The Masters (1951) el paraíso idílico y aislado de su protagonista y narrador Lewis Elliot en el mundo académico en el que vive encerrado y del que será perturbado al verse implicado en el nombramiento de un nuevo director del college. Por su parte, Lucky Jim (1954) de K. Amis sitúa la acción en una universidad de provincias, y relatada en tercera persona sigue las andanzas de un profesor de historia medieval, Jim Dixon, mediocre y sin sentido del trabajo sometido a un jefe pretencioso no mucho mejor que él. La novela de Amis se tiñe de humor -presente en seguidores del género como Tom Sharpe o David Lodge-, mientras que la de Snow recrea idílicamente la superioridad intelectual de las instituciones universitarias de más prestigio, Oxford y Cambridge. En este sentido, señala Castagnino (2011:127):

Se ha propuesto que la novela de Snow tiene que ver más bien con el cierre de una era donde la educación universitaria tenía un valor intrínseco que teñía de atractivo, interés e incluso heroicidad a quienes estaban a cargo de ella (SHOWALTER, 2005: 22-23). Se entiende también que Amis hace un gesto fundacional más profundo en cuanto siembra en su texto el desencanto social de los jóvenes de clase trabajadora que acceden por primera vez a la educación universitaria, desencanto que florecerá en novelas académicas posteriores. 
The Groves of Academe (1952), de Mary McCarthy y Pictures from an Institution (1954), de Randall Jarrell son las novelas primeras del género en Estados Unidos y presentan notables diferencias con respecto a las británicas arriba reseñadas (Mosely 2007: 187-204). Ambas se localizan en instituciones académicas privadas como son los liberal arts colleges. La primera, narrada en tercera persona, relata los esfuerzos de su protagonista el profesor Henry Mulcahy por no ser despedido y en consecuencia al conseguirlo, el hundimiento de la institución como garante de la verdad. En la segunda novela, Jarrell monta una novela en torno a Benton College donde el narrador en primera persona relata sin argumento aparente la experiencia del personaje de Gertrude Johnson cuando llega allí a impartir docencia un semestre.

Dado el incipiente estado del género, se han adoptado distintos sintagmas para nombrar al conjunto de obras que se incluye en lo que hemos optado por denominar novelas de campus, pues además de este marbete, aparecen con frecuencia otros como novela universitaria, novela académica o novela de la vida universitaria. Así, Patricia Moore-Martínez, autora de una tesis doctoral acerca de la novela de campus en España (The Emergence of the Spanish Peninsular Campus Novel), prefiere denominar a las obras que integran el género novela de campus "but the term campus novel, in my opinion, best identifies the genre as one which has a spatial as well as a conceptual connotation e term campus novel, in my opinion, best identifies the genre as one which has a spatial as well as a conceptual connotation” (2009:4). Otras respuestas a esa variedad terminológica tienen que ver con la distinción entre obras centradas en el mundo de los estudiantes o mundo del profesorado:

Sin embargo, debemos distinguir las "novelas de universidad" o "college novels", como las que acabamos de citar, y las "novelas de campus", como subgénero específico aparecido después de la Segunda Guerra Mundial. La principal diferencia literaria entre ambas, a grandes rasgos, radicaría en que mientras las primeras son esencialmente novelas de formación (Bildungsroman) -centradas en el estudiante y escritas por autores que no son académicos de profesión- las segundas se centran en la figura del profesor y sus contradicciones respecto a la misma institución, además de estar escritas, la gran mayoría de ellas, por docentes universitarios ${ }^{1}$.

Aunque la imprecisión léxica tiene mucho que ver con la ambigüedad genérica, coincido con el sintagma "novela de campus", incluyente tanto del mundo de los estudiantes como de los profesores, entre otras razones porque, como 
veremos, en las novelas últimas publicadas en España, el mundo universitario no centra el argumento, sino sólo el entorno espacial, y se suma al hecho de estar escritas, en su mayoría, por docentes. Con todo, se pueden extraer algunos rasgos comunes a estas novelas de campus que las aúnan dentro de una categoría narrativa perfectamente identificable frente a otras dentro de las formas de la narrativa actual. $\mathrm{Si}$, como he señalado, su forma y técnica narrativa es diversa, tienen en común el hecho de que la universidad es su marco narrativo, donde todo sucede.

La naturaleza y características de la universidad en el Reino Unido y en Estados Unidos -que difiere en mucho del modelo español-, permite el tratamiento de tramas ficcionales muy centradas en el mundo académico. Allí se produce una convivencia más estrecha entre los miembros de la comunidad universitaria, que en la mayor parte de los casos viven en el campus, existen hermandades-fraternidades, tiene lugar una, más que cercana y en ocasiones hospitalaria, relación entre los profesores y es también más inmediata la conexión profesor-estudiante. Estos son algunos de los factores que propician la proximidad entre la vida profesional y la vida privada, hasta el punto de que estas ficciones universitarias presentan un micromundo cerrado con sus propias normas de funcionamiento cuyo comienzo y final está en la propia institución académica. Por otro lado, esa narrativa de campus anglo norteamericana desarrollada a partir de los años 50 del pasado siglo se desenvuelve principalmente entre dos polos argumentales: de un lado, la nostalgia de una vida académica ya pasada, pero siempre rememorada idílicamente, en la que vocación y esfuerzo compiten y en la que el desarrollo intelectual es un fin en sí mismo, y de otro, una mirada cargada de ironía y humor, a veces muy ácido, hacia el mundo universitario, en el que todos sus estamentos: profesorado, estudiantes y personal administrativo son objeto de burla o ridiculización con el fin de denunciar la vaciedad en la que la más alta cumbre del conocimiento ha llegado.

La literatura española presenta ciertas peculiaridades en la acogida de un tipo de novelas cuya principal característica es el reflejo de la vida universitaria, con sus virtudes y sobre todo sus vicios, pero es poco riguroso negar su existencia. Estudios recientes como los de J. García Rodríguez (2002 y 2015) o L. Villamía (2015) se centran en el análisis de diversos aspectos de la novela de campus o académica en el contexto español, en el humor y la sátira el primero, y en la autoficción el segundo, abogando en ambos casos por la demostración de la existencia genérica a partir de unas características permeables que muestran las novelas integradas en el grupo. La circunstancia histórica determina en gran medida el desarrollo literario de un periodo, estilo o género literario, y es la historia de España desde finales del XIX hasta la actualidad la que establece en este caso la configuración de la novela de campus o su no existencia hasta 
tiempos recientes. Pues Pío Baroja, con El árbol de la ciencia, Nada, de Carmen Laforet, o La Colmena de Camilo José Cela, que son algunos de los textos apuntados como antecedentes de la narrativa universitaria, no son sino pequeñas calas alusivas a un mundo universitario cerrado, que tras la guerra civil y la llegada de la dictadura de Franco, se convierte en un campo inexpugnable y poco conveniente a las tramas narrativas de la ortodoxia. Por ello, no ha existido un desarrollo consolidado de la temática universitaria en nuestro país, y solo tras el afianzamiento de la democracia y de la libertad de los autores para elegir temáticas y posibilidades técnicas en la narrativa ha sido posible que la novela de campus conozca un desenvolvimiento en la literatura española. Y este proceso es especialmente patente en lo que llevamos de siglo XXI. En este sentido F. J. García Rodríguez, después de un recuento de alguna de las obras significativas que pueden ser englobadas bajo la denominación de novela de campus, apunta:

Pero sí es significativo cómo la enumeración nos permite reconocer a autores que cubren prácticamente todas las promociones que tienen actividad literaria actualmente, así como una variadísima adscripción estilística. Esto es, el sistema género "novela de campus" ha alcanzado un estado de institucionalización que permea estilos y generaciones, de tal modo que, más allá de sus diferencias evidentes y su escasa presencia, aparece integrado en el sistema literario español con naturalidad (2015: 281).

Como en toda agrupación genérica, también en la novela de campus hay que buscar unos orígenes que en el caso español presentan determinadas características. Un primer problema tiene que ver con que la mayoría de las veces las novelas han sido clasificadas bajo otros membretes genéricos, olvidando de este modo que su contextualización "universitaria" es fundamental. Hay que apuntar que la vida académica en España no se presenta como un cosmos consolidado y cerrado en el que trabajo y vida se entremezclan, entre otras circunstancias porque en general no existe convivencia: al campus se va a trabajar o a estudiar, pero no a vivir. Esta realidad impide una novela de campus que desarrolle todas las posibilidades de sus precedentes en Inglaterra o Estados Unidos, y al mismo tiempo, favorece otro tipo de tramas que se entremezclan o tienen lugar en la universidad pero que, sin embargo, no se relacionan directamente con ella, como veremos en alguno de los ejemplos elegidos.

Las novelas de campus publicadas en España entre 2000-2015 alcanzan un número significativo, y si bien presentan rasgos diferentes entre sí, están ubicadas en un entorno universitario que condiciona su forma y contenido. El corpus elegido, que recoge alguna de las variantes argumentales del género, contiene 
los siguientes títulos: Josefina Aldecoa: El enigma (2002), Javier Cercas: La velocidad de la luz (2005), Lourdes Ortiz: Las manos de Velázquez (2006), Antonio Orejudo: Un momento de descanso (2011), Carmen Riera: Naturaleza casi muerta (2012), Álvaro Pombo: El temblor del héroe (2012); a ellas hay que añadir las obras ganadoras del premio de narrativa de novela de campus El tren de cristal (2011) de José María Pérez Collados y Química del odio (2013) de Ignacio Díaz. Llama la atención la nómina de autores de estas novelas, a los que caracteriza el hecho de ser escritores consagrados y docentes todos ellos menos Pombo, cuya novela, por otro lado, no se puede considerar de campus en sentido estricto, como tampoco La velocidad de la luz, de Cercas publicada en 2005, ya que en ambos casos la vinculación académica es insignificante en fondo y en forma. En cuanto al resto se trata de autores que conocen bien el mundo de la docencia y que por ello están especialmente dotados para su análisis, elogio o crítica, porque escriben desde dentro. Por otro lado, las novelas citadas no tienen en común sino el marco universitario en el que se desarrollan y que en general exponen el desaliento al que la vida académica aboca a quien la vive, puesto que como a continuación expongo, presentan temáticas y desarrollos argumentales diferentes.

Los precedentes españoles inmediatos de este corpus han sido sobradamente analizados y resultan fundamentales para seguir la evolución del mismo; algunos de ellos de tono algo menor pero no por ello menos interesantes, como La muerte del decano, de Gonzalo Torrente Ballester, de 1992, en la que la muerte de un decano convierte la novela en un relato policial, o Carlota Fainberg, de Antonio Muñoz Molina, de 1999. De entre ellas quiero destacar Todas las almas, de Javier Marías de 1989, novela que introduce de lleno una de las variantes temáticas fundamentales de la novela de campus española como es la presencia de profesores españoles en universidades británicas o americanas, en este caso en Oxford. La obra es en cierto modo un trasunto biográfico del propio Marías, que también pasó varios años enseñando en Oxford, realizado a través de un narrador autodiegético que se mueve en distintas instancias temporales. Y es que efectivamente, a la consolidación de la democracia sigue la apertura del sistema universitario al exterior, de manera que a partir de los años 80 ya es posible hablar de estancias para docencia e investigación de profesores y estudiantes españoles en centros extranjeros, hecho que permite en consecuencia ficcionalizar esa realidad.

De las novelas propuestas a análisis desde el año 2000 la primera cronológicamente es El enigma, de Josefina Aldecoa, publicada en 2002. La trama es sencilla solo en apariencia, pues se centra en Daniel Rivera, profesor universitario de Madrid que va a pasar un semestre en una universidad del noroeste de los Estados Unidos; casado con Berta y padre de dos hijos adolescentes, 
la salida hacia su nuevo destino temporal se va a convertir en un revulsivo no solo profesional sino también y principalmente personal. Allí conoce a Teresa, hija de un profesor exiliado durante la dictadura franquista, que le descubre una nueva forma de entender el trabajo, la vida académica y cultural, las relaciones laborales y sobre todo, la pasión. Este argumento da pie a Aldecoa a reflexionar acerca de todo lo que ella bien había trabajado como pedagoga y como gran conocedora del mundo educativo, pues su texto contiene un sinfín de referencias a la educación, al compromiso intelectual, a la libertad de pensamiento que otorga el conocimiento, y también a la creación, pues Daniel quiere ser poeta. Hay en esta novela otra línea argumental complementaria que es la comparación entre el mundo académico español y el americano; Daniel es el responsable de establecer ese cotejo a través de las mujeres que de una u otra forma ocupan su vida: el carácter emprendedor y positivo que encuentra en Teresa y lo regresivo y retrógrado que halla en Berta, su mujer.

El mundo universitario americano, con sus defectos, se presenta auténtico en todos los sentidos, incluso cuando habla de los estudiantes, frente al sistema español, cargado de negatividad (Patricia Moore-Martínez, 114 y ss). El conocer a Teresa, tanto desde el punto de vista afectivo y sexual, como intelectual y cultural, lleva al protagonista a considerar un error su matrimonio con Berta, dedicada al cuidado de casa e hijos alejada de entornos intelectualmente válidos y de la que escucha comentarios como:

Lo que tú quieras, muchos libros, mucha colaboración, muchos cursos pero yo te digo que el cuñado de Rosa, Luisa, Julia, no importaba de quién, hace negocios fabulosos con un primo que es director de banco... Y no tiene cultura ni educación ni nada.... (75)

Frente a ella, la opinión de Teresa:

En las conversaciones con amigos, en la Universidad, en Nueva York, Daniel era incisivo, brillante. Era el Daniel profesor, ensayista, poeta que opinaba en un plano elevado y revelaba el conocimiento del mundo cultural que ocupaba la mayor parte de su tiempo. Y cuando conversaban ellos dos, Teresa valoraba la calidad de la relación intelectual que les unía, la indagación paralela de la realidad, los hallazgos de la imaginación. No dudaba del Daniel intelectual. Tampoco dudaba de la pasión. (100) 
Por este camino el texto enfrenta dos realidades "académicas" y sentimentales radicalmente opuestas, en un interesante ejercicio de reflexión. Aun así, la novela presenta algunas deficiencias, como el hecho de que la personalidad del protagonista sea vacilante, no del todo honesta, y que la novela en conjunto esté sobrecargada de ciertos momentos de intimidad, a veces algo almibarados, que sin embargo no empañan el asunto principal de la obra: la reflexión, en todos sus ámbitos vitales, de un profesor universitario que tiene la oportunidad de vivir una experiencia americana que le hará replantearse toda su existencia. Estructuralmente, la novela se halla fragmentada en dos partes simétricas en cuanto a extensión, que dividen la estancia del protagonista en América y el encuentro con el mundo académico americano y con Teresa, y su regreso a España, en la segunda parte, y su colisión con la realidad familiar y universitaria en nuestro país. Narrada en tercera persona y de forma lineal, El enigma es una novela que con mayor o menor acierto relata la crisis existencial de un profesor de 48 años, crisis que se ve confirmada al enfrentar dos mundos intelectuales, académicos y sentimentales opuestos, en los que el sistema español sale muy mal parado, pero que paradójicamente es en el que el protagonista finalmente se queda. La obra en su conjunto no se escapa de su adscripción académica, pero la sobrecarga sentimental entorpece en ocasiones las posibilidades de una trama, la confrontación intelectual y en consecuencia vital, de un profesor español que tiene la oportunidad de conocer el sistema universitario americano.

Lourdes Ortiz publica en 2006 Las manos de Velázquez, novela que nunca ha sido catalogada de campus y que considero lo es, puesto que su trama es impensable sin el necesario aporte contextual del mundo universitario en el que tiene lugar la historia, y dentro de ésta, la investigación. Es sin duda la novela más culta, erudita y de mayor calado literario de cuantas se han considerado para este trabajo, porque Lourdes Ortiz, profesora de Arte, ha realizado en este texto un análisis concreto de las relaciones entre literatura y pintura verdaderamente excepcional. Ha sido José Enrique Martínez quien mejor ha estudiado esta novela y quien acertadamente ha expuesto los caminos por los que la obra de Ortiz debe ser considerada una importante aportación a la narrativa española actual (2009: 49-70). Teodoro es un profesor universitario de Arte que está realizando un trabajo de investigación sobre Velázquez con la intención de conseguir aportar algo nuevo a lo ya dicho y sabido del genial pintor español: "Teodoro se nos aparece, como acabo de indicar, obsesionado por captar el espíritu de Velázquez, por hacer algo nuevo, por no repetir lo ya sabido y expresado" (Martínez, 2009: 50). Nada ajeno a cualquier persona vinculada a la investigación de un departamento universitario que busca aportar nuevas visiones a temas ya tratados. 
En el ámbito personal, Teodoro está casado en segundas nupcias con Mónica, antigua alumna, mucho más joven que él y su contrapunto en todos los aspectos. A partir de este planteamiento, la novela se mueve en varias esferas temporales y grados de focalización para, por un lado, convertir la investigación acerca de Velázquez en asunto narrativo, y por el otro, conocer la difícil situación personal por la que Teodoro está pasando. En esta obra es fundamental la descripción detallada de la ansiedad, inseguridad y obsesión de la investigación universitaria cuando ésta es rigurosa, en la que como en este caso y siguiendo el pensamiento del personaje principal, se llega a producir una identificación entre investigador y objeto investigado, unido a una crítica descarnada al sistema universitario:

El ascenso a la cátedra. Más sueldo y más prestigio. Y, sobre todo, años de espera, de papeles, de horas y horas de clases, de seminarios, de... La culminación de una carrera. Un profesor discreto, callado también como Diego, con pocas publicaciones y harto de tragar y tragar, de comulgar con ruegas de molino. Sonreír. Sonreír y soportar. La cátedra o la cruz de Santiago. Viene a ser lo mismo. Lo que a uno se le debe después de mucho tiempo, de contemplar a los lameculos, mediocres, papanatas que se pavonean de su ignorancia y su incapacidad para ver más lejos. Ratoncillos de biblioteca que repiten como papagayos. Pero ¿'soy yo acaso mejor que ellos, diferente?” (9).

Las manos de Velázquez no muestra los conflictos habituales del profesor universitario en su faceta de docente, sino que de forma muy original, Lourdes Ortiz aborda esa otra cara del académico, la de investigador, de la que se habla mucho menos en la novela de campus. Y como la investigación de Teodoro es de pintura y en concreto Velázquez, la autora aprovecha su trama para desplegar un torrente de conocimiento y sabiduría de arte y de cómo ver la obra artística. En este sentido la novela es calificada de culturalista y erudita, y sin descalificar esta clasificación genérica, considero que Las manos de Velázquez es, como antes señalé, una novela de campus, puesto que se centra, más allá de la anécdota concreta de su historia, en los vericuetos y laberintos de la investigación en la universidad. Y además, es la primera que lo hace.

Antonio Orejudo publica Un momento de descanso en 2011, después de una exitosa incursión en la narrativa española con Fabulosas narraciones por historias (1996), celebrada por la crítica y por los lectores y donde ya aparecía en toda su extensión el humor ácido, mordaz, y en ocasiones soez, que preside alguno de sus textos. Un momento de descanso es una novela que conecta directamente con la tradición anglo-norteamericana del género en su vertiente humorística, aún 
sin abandonar un poso de drama que va a ser constante en este tipo novelas. En sus páginas, Orejudo narrador se reencuentra, después de diecisiete años, con su colega y amigo Cifuentes, quien le contará su andadura por los Estados Unidos, tanto desde el punto de vista profesional como personal, y las razones que le han hecho volver a España. En la primera parte de las tres de que consta la obra se produce el encuentro entre los dos antiguos amigos, Orejudo y Cifuentes, en Madrid en 2009; Cifuentes le relatará entonces su desgraciada peripecia por Estados Unidos, en donde ambos habían convivido en sus primeros pasos como docentes. Cifuentes refiere entre humor y amargura, un periplo personal infortunado, con la ruptura de su matrimonio y la realidad de su hijo discapacitado, Edgar, para luego introducirse de lleno en la vida universitaria americana, en este caso en Missouri. En esta parte de la novela, el autor carga contra el sistema americano y los tópicos políticamente correctos bajo el que se sustenta, en una interesante mezcla de ironía y dolor. Por otro lado, este paso por la universidad americana acaba destrozando a Cifuentes, por lo que a su vuelta a España como docente en la universidad en la que estudiaron, ya en la última parte de la novela, idea un plan para acabar con una injusticia del pasado, con la ayuda de su antiguo amigo Orejudo, consistente en desenmascarar a Augusto Desmoines, gran "pope” y tutor de ambos en sus años de estudiantes. En el centro, la aventura creadora de Orejudo, la escritura como centro temático que, al igual que en las otras dos partes, se halla presidido por la certeza de que en la vida nada es lo que parece ser.

Desde el punto de vista que abordamos en estas páginas, la novela de campus en España, la novela de Orejudo es un ejemplo paradigmático, pues bebe de la mejor tradición anglo norteamericana del género, sin olvidar la ironía y el sarcasmo, pero introduce también los vicios en los que ha incurrido la institución en España. Además, los protagonistas son estudiantes de Filología Hispánica, que como se ha señalado anteriormente, las novelas de campus se centran en las áreas de Humanidades, en palabras del narrador:

Filología Hispánica aún no se había convertido en una carrera de saldo, aún no era la licenciatura de los que no pueden estudiar algo más serio por falta de capacidad o de nota media. Cuando nosotros entramos en la universidad, Filología Hispánica era todavía una disciplina en la que se matriculaban no sólo quienes no servían para las ciencias, sino también jóvenes de cierta cultura, chicos a los que les interesaban de verdad las letras, y que habían leído bastantes libros para su edad. (98) 
Y más adelante:

En menos de cinco años el estudio de la literatura, esa tarea a la que habíamos consagrado nuestros años universitarios, pasó de ser una prestigiosa ocupación cuya utilidad nadie cuestionaba a considerarse una disciplina inútil que sólo conducía a la frustración y al paro. (99)

Y unido a esta crítica, la ausencia de novela de campus en España a causa de que en Universidad española, al contrario que en la anglosajona, todos los vicios son puestos al descubierto:

\begin{abstract}
¿Nunca se ha parado a pensar por qué apenas se han escrito novelas de campus en español? Yo se lo voy a decir: porque es imposible escribir una novela sobre la universidad española, que sea elegante y además verosímil. Lucky Jim, de Kingsley Amis, o Small World, de David Lodge, son tan buenas porque la universidad que toman de referencia, la anglosajona, conserva todavía unas formas impecables, aunque por dentro esté consumida por las mismas corruptelas que la de aquí. En la universidad española por el contrario la grosería aparece tal cual, sin los ropajes de la buena educación.
\end{abstract}

Por su estilo, contenido y afirmaciones como las reproducidas arriba, Orejudo es el escritor de campus más consciente de estar escribiendo eso mismo, una novela de campus, que aparece como telón de fondo argumental metaliterario, o mejor, "metagenérico", porque con ello el escritor está reflexionando acerca del propio género, su escritura y su misma existencia. En este sentido, y a pesar del exceso en ciertos pasajes, la novela es una muestra única hasta la fecha de novela de campus en España.

Con tono radicalmente distinto se presenta Naturaleza casi muerta, de la profesora y escritora catalana Carme Riera, publicada en 2011. En este caso se trata de una novela de campus con una trama de tipo policiaco-criminal, cuyo contexto espacio-temporal es muy cercano, pues se sitúa en época actual y en el campus de la Universidad de Barcelona. En su facultad de Letras desaparece un estudiante Erasmus rumano y a partir de ahí se suceden, de diferentes maneras, una serie de asesinatos. La trama es propia de novela negra, pero al estar ubicada en la universidad, los caracteres son los propios de una facultad: decana, estudiantes, otros profesores, la encargada de los estudiantes Erasmus, el becario, el catedrático déspota y todo poderoso..., es decir, en esta novela encontramos todo el espectro profesional de la carrera universitaria en sus diferentes modalidades, sus vicios y deficiencias. Al comienzo del relato y a modo de prólogo, la autora sitúa el espacio que es elemento esencial en toda novela policiaca, y como antes se ha señalado, también en la de campus, detallando las características de la Universidad de Barcelona: 
El campus de la Universidad Autónoma de Barcelona ocupa una extensión de 263 hectáreas de las que 230 corresponden a espacios verdes. Limita, al norte, con Bellaterra; al sur, con Cerdañola del Vallés, municipio al que pertenece; al este, con Badia del Vallés y Sabadell, y al oeste, con San Cugat del Vallés y Bellaterra. Cruzado por 21 kilómetros de vías principales y por tres ejes: Norte, Central y Sur, acoge a 40.000 estudiantes, 3.688 profesores y 2.340 PAS (personal de administración y servicios) (8).

Y relaciona el espacio real con el espacio ficcional, lo que otorga un carácter realista a la narración que se propone contar:

La facultad de Filosofía y Letras, donde transcurre una gran parte de esta novela, está situada en el sudeste del campus, muy cerca de la biblioteca de Humanidades, y comparte con la facultad de Psicología y la de Económicas el Edificio B. Son también lugares importantes de nuestra historia el camino que, saliendo del aparcamiento de Letras, conduce a través de un pequeño bosque hasta Ciudad Badia, el edificio del Rectorado, los apartamentos de la Vila y el hotel Serhs, situados estos últimos al noroeste. Desde la Vila se puede llegar a la facultad de Letras dando un paseo o en el autobús que recorre el complejo universitario, tal y como solían hacer Laura Cremona y Domenica Arrigo, personajes fundamentales de la narración (9).

Por otro lado, estos asesinatos llevados a cabo en dicho entorno universitario se relacionan con la pintura del artista alemán Flegel, del que se describen con minuciosidad sus cuadros de naturalezas muertas, uno de los cuales da título a la novela. Y el asesino, después de las pesquisas policiacas, admite su crimen por un asunto de venganza que devuelve la trama de la novela al campus que le da origen, porque en la resolución de los crímenes hay un caso de abuso de poder del catedrático hacia el becario:

Sin embargo, él, con aire ausente, le aseguró que le daba igual lo que pudiera pasarle y aceptó que había matado a Bellpuig, harto de sus humillaciones, harto de que le llamara a cualquier hora para encargarle que le hiciera fotocopias o le fuera a buscar libros a la biblioteca, harto de que le endosara las clases y, encima, no reconociera sus servicios y quisiera echarlo de la universidad, negándose a que continuara de becario.

Había matado a Bellpuig y antes a las dos Erasmus y después a Bru, lo aceptaba como efectos colaterales. Si mataba también a los alumnos era difícil que creyeran que el autor era él, porque en realidad él sólo quería vengarse de su profesor y no de los otros (425).

Escrita de forma lineal siguiendo las pautas de la investigación policial y con un narrador omnisciente, la novela de Riera presenta así una modalidad temática 
dentro de la novela de campus, la de tipo policiaco, y tiene la virtud de centrarse en un campus español, con lo que se demuestra que actualmente el contexto académico universitario español ya está maduro para protagonizar novelas de campus cuya materia puede ser variada: sentimental, cultural, policiaca, filosófica.

De lo expuesto se pueden extraer indudablemente varios rasgos de género que señalan la existencia de una nueva tendencia en la narrativa española actual. El mayoritario acceso a los estudios universitarios en la actualidad, la modernización de la propia institución, la variedad de sus miembros, entre los que se hallan personas de fuera del país, o la movilidad de docentes y estudiantes españoles a campus extranjeros, han sido las causas inmediatas del auge de esta variedad narrativa. En ella se puede encontrar gran variedad argumental, puesto que la agrupación genérica se debe al contexto espacio- temporal, es decir, un campus universitario en tiempos actuales. Esta circunstancia favorece que aun con tramas diversas, los problemas de la universidad aparezcan reflejados con mayor o menor profusión de datos, pero siempre están presentes. Además, y el futuro desarrollo del género confirmará o rechazará esta premisa, hasta la fecha este tipo de novelas han sido escritas por autores vinculados a la universidad, casi siempre como docentes, lo que corrobora el realismo de los textos, puesto que sus artífices son buenos conocedores de lo que narran, y aun ficcionalizado, hay en todas ellas una cercanía a la realidad que no es ajena a los lectores que conocen la institución universitaria española por dentro. Ello supone que también desde el punto de vista de la recepción, son sus lectores "ideales" precisamente estos últimos, pues resulta de otro modo inverosímil el relato de los vicios en los que ha incurrido tan alta casa del saber.

De los cuatro ejemplos analizados es destacable la distinta temática que abordan e incluso la multiplicidad de formas narrativas que en ellas se leen, y con todo, es la Universidad y su estructura la que les da sustento a todas ellas y sin la cual no serían como son. Junto a estos elementos aparece en estas novelas cierta amargura, pues de sus páginas se desprende la sensación de derrota y tristeza que en ocasiones produce el mundo académico universitario en el contexto español a quien transita de una u otra forma por él.

\section{Bibliografía}

ALDECOA, J. (2002). El enigma. Madrid: Alfaguara.

AMIS, K. (1954). Lucky Jim. New York: Victor Gollancz.

BAENA MOLINA, R. (1997): “Campus novel: paradigmas de un género novelístico en Inglaterra” en Unum et diversum: estudios en honor de ÁngelRaimundo Fernández González. Pamplona: Eunsa: 79-95. 
BOU, E. (2006). “Campus universitarios: deriva y simulacro”. Lars. Cultura y Ciudad (5): 6-7

BOURDIEU, P. (2008). Homo academicus. Buenos Aires: Siglo XXI.

CASTAGNINO, M ${ }^{\mathrm{a}}$ I. (2011). "Novela académica: reflexiones sobre sus orígenes en Inglaterra y Estados Unidos” en Actas de las X Jornadas de Literatura Comparada. <http://xjornadaslc.fahce.unlp.edu.ar/> (Acceso 19 de mayo 2015).

CERCAS, J. (2000). El inquilino. Barcelona: El Acantilado.

CERCAS, J. (2005). La velocidad de la luz. Barcelona: Tusquets.

CERCAS, J. (2007). El vientre de la ballena. Barcelona: Tusquets.

CONCHA, Á. de la (1988). "La novela universitaria: foro de teorías sobre la ficción y de ficcionalización de teorías”. Revista Canaria de Estudios Ingleses 17: 169-196.

DÍAZ, I. (2013). Química del odio. Sevilla: Renacimiento.

GARCÍA RODRÍGUEZ, J. (2002). “Apuntes para la caracterización de la literatura de campus con un muestrario (necesariamente) incompleto de obras”. Clarín. Revista de Nueva Literatura 37: 3-13.

GARCÍA RODRÍGUEZ, J. (2015). "Escribe cien veces: “no me reiré de los profesores”. (Humor, sátira académica y novela de campus reciente en España)”. Pasavento. Revista de Estudios Hispánicos 3(2): 273-293.

GUILLÉN, C. (1985). Entre lo uno y lo diverso. Introducción a la literatura comparada. Barcelona: Crítica.

JARRELL, R. (1954). Pictures from an Institution: A Comedy. New York: Alfred A. Knopf.

LAMBERTSSON BJÖRK, E. (1993). Campus Clowns and the Canon: David Lodge's Campus Fiction. Umea: The Printing Office of the University of Umea.

LEUZINGER, MIRJAM, A. (2014). "Realidades imaginadas y academia: Un momento de descanso de Antonio Orejudo” en Las sombras del novelista: Autorrepresentaciones (ed. Antonio J. Gil González). Dijon: Editions Orbis Tertius: 219-230.

LYONS, J. O. (1962). The College Novel in America. Carbondale: Southern Illinois University Press.

MARÍAS, J. (1989). Todas las almas. Madrid: Anagrama.

MARTÍNEZ, J. E. (2009). “Alguien que trabaja con las manos y se las mancha. Las manos de Velázquez, de Lourdes Ortiz” en Musas hermanas: Arte y Literatura en el espejo del relato (coord. S. Gil, A. Pérez-Pedrero y M. Rodríguez Pequeño). Nueva York: Cátedra Miguel Delibes: 49-70.

MCCARTHY, M. (1952). The Groves of Academy. San Diego: Harcourt Brace. MOORE-MARTÍNEZ, P. (2009). The Emergence of the Spanish Peninsular Campus Novel. Philadelphia: Temple University. 
MOSELEY, M. (Ed.) (2007). The Academic Novel: New and Classic Essays. Chester: Chester Academic Press.

MUÑOZ MOLINA, A. (1999). Carlota Fainberg. Madrid: Alfaguara.

OREJUDO, A. (2011). Un momento de descanso. Barcelona: Tusquets.

ORTIZ, L. (2006). Las manos de Velázquez. Barcelona: Planeta.

PÉREZ COLLADOS, J. M. (2011). El tren de cristal. Sevilla: Renacimiento.

POMBO, A. (2012). El temblor del héroe. Barcelona: Destino.

RIERA, C. (2012). Naturaleza casi muerta. Madrid: Alfaguara.

ROSSEN, J. (1993). The University in Modern Fiction: When Power is Academic. Nueva York: St. Martin's Press.

RUEDA, A. (2014). “Autoficción y novela en clave: Un momento de descanso de Antonio Orejudo" en El yo fabulado. Nuevas aproximaciones críticas a la autoficción (ed. A. Casas). Madrid/Frankfurt: Ibertoamericana/Vervuert: 289-305.

SHOWALTER, E. (2005). Faculty Towers: The Academic Novel and Its Discontents. Philadelphia: University of Pennsylvania Press.

SNOW, C. P. (1951). The Masters. London: Penguin Books.

TORRENTE BALLESTER, G. (1992). La muerte del decano. Barcelona: Planeta.

VILLAMÍA, L. (2015). "El despliegue de la autoficción en la academia: La novela de campus en la narrativa actual”. Pasavento. Revista de Estudios Hispánicos 3(1): 43-55.

WOMACK, K. (2002). Postwar Academic Fiction: Satire, Ethics, Community. Houndmills: Palgrave. 